\title{
Success Factors for E-Livestock: An E-Government Initiative
}

\author{
${ }^{1}$ Arief Ramadhan, ${ }^{1}$ Dana Indra Sensuse, ${ }^{2}$ Muladno and ${ }^{1}$ Aniati Murni Arymurthy \\ ${ }^{1}$ Faculty of Computer Science, University of Indonesia, Depok, Indonesia \\ ${ }^{2}$ Faculty of Animal Science, Bogor Agricultural University, Depok, Indonesia
}

Received 2013-01-20, Revised 2013-04-03; Accepted 2013-05-03

\begin{abstract}
E-Government system has been developed in various countries. Currently, e-Government specifically appears in various paradigms, such as e-Procurement, e-Voting. Lastly, has emerged a new paradigm in e-Government, called e-Livestock. Therefore, in this study, we will propose and discuss about several success factors for eLivestock in Indonesia. We will take into account four previous researches that are related to this research. Based on four previous researches, we compose first round questionnaire that consists of 65 suggested success factors. We also compose second round questionnaire that consists of 14 suggested success factors. We combine and analyzed the result of both questionnaires, so that we get 62 success factors for e-Livestock in Indonesia. We propose that in practice, to make their initiative success, all of the 62 success factors that resulted from this research have to exist and be accommodated by all parties that involved in the e-Livestock initiative in Indonesia.
\end{abstract}

Keywords: Success Factors, E-Livestock, E-Government

\section{INTRODUCTION}

There are some definitions about e-Government. According to the WB (2011), e-Government refers to the use by government agencies of Information Technologies (IT) that have the ability to transform relations with citizens, businesses and other arms of government. Other definition of e-Government is defined as capacity to transform public administration through the use of Information and Communication Technologies (ICTs) or indeed is used to describe a new form of government built around ICTs (Wang and Zeng, 2009).

E-government has become an emergent multidisciplinary field of research (Assar et al., 2011). Although theoretical ground is still under construction, eGovernment certainly qualifies as a legitimate emerging scientific discipline (Assar et al., 2011). The research field of e-government is rather broad and several researchers have involved in a range of different research projects on different topics within the field (Lofstedt, 2008).
Heeks (2006) says that e-Government is also an information system, but it is enriched with various aspects, such as the management aspects, political aspects and others. In addition, ordinary information system is generally targeting the private sector and intended to maximize financial income, but the main orientation of e-Government is the accessibility of information by the public (Heeks, 2006).

E-Government system has been developed in various countries. Currently, e-Government specifically appears in various paradigms, such as e-Procurement, e-Voting. Some related researches have been done to those paradigms. Lastly, Ramadhan and Sensuse (2011) have proposed a new paradigm in e-Government, called eLivestock and become the main concern in this research.

As the name imply, e-Livestock is closely related to e-Government in the field of livestock. Ramadhan and Sensuse (2011) have tried to explain the e-Livestock in general. Furthermore, Ramadhan et al. (2012a) have conducted a research to formulate the e-Livestock definition for Indonesia. The newest research is what has

Corresponding Author: Arief Ramadhan, Faculty of Computer Science, University of Indonesia, Depok, Indonesia 
been conducted by Ramadhan et al. (2012b). In that newest research, they adjust the definition of e-Livestock for Indonesia and they revealed the expected benefits and challenges of e-Livestock in Indonesia.

However, up to now, there has been no research that proposes or discusses about the success factor for eLivestock, especially that specific for Indonesia. Therefore, in this study, we will propose and discuss about several success factor for e-Livestock in Indonesia. We will extract what are the success factors for eLivestock in Indonesia and validate those success factors to several stakeholders and experts in livestock field and e-Government field in Indonesia.

\subsection{Research Background}

Indonesia is a country with a very large population. Based on the result of 2010 population census, the population of Indonesia in 2010 is 237,641,326 inhabitants (BPS, 2011). The population is increased by $13.20 \%$ from 2000 . The increased population means demand for food resources is also increasing.

Food consumed by the population can be either sourced from vegetable or meat. Meat can be obtained from Fish, Chicken, Cattle, Buffalo, Pig, Goat and others. Based on the results of the National Economic Census, in 2007 and 2008, it is known that the consumption of fresh meat derived from cattle (beef) ranks second after the consumption of fresh meat from chicken (DGLAH, 2009).

The need for beef is increasing from year to year. But unfortunately, the national beef supply is not able to meet those needs. In 2010, according to Minister of Agriculture, Suswono, the national beef supply can only meet $68 \%$ of all the needs that exist and the rest are fulfilled through imports (Malau, 2010).

The government has made various efforts to reduce imports and achieve self-sufficiency in beef, for example by opening various beef cattle breeding center, open the Superior Livestock Research Institute (BPTU) in various provinces and open the Regional Artificial Insemination Center (BIBD). Government of Indonesia through the Directorate General of Livestock and Animal Health has also launched the Beef Self-Sufficiency Program (PSDS) twice, i.e., PSDS 2005 and PSDS 2010. However, the targets of both PSDS are missed, which failed to achieve self-sufficiency in beef, so that imports still continue.

Currently, the Indonesian government has launched the new PSDS, i.e., PSDS 2014. The government has issued a blueprint of the PSDS 2014 (DGLAH, 2011). The definition of self-sufficiency in that blueprint is the ability of the domestic supply of beef by $90-95 \%$. Based on that blueprint, there are 5 main activities and 13 operational activities in PSDS 2014. The program about prevention of slaughtering the productive cow is also included in that blueprint. However, in that blueprint, there is no main activity that associated with a good registration of cows in Indonesia. Whereas, good registration can produce accurate data, so that the decision-making in the livestock sector can be done quickly and precisely, for example in terms of policy making about how many cows have to be imported in one year.

Therefore, we need a system in which data collection can be done all the time. The system can utilize ICT that applied extensively in the country level. The system also must be able to report meaningful data. Reporting a concrete and correct data on cattle populations could open a new hope that the multi-year projections, to achieve food security based on livestock domestic resources no longer dreamily (Sinjal, 2011).

Ramadhan and Sensuse (2011) have proposed that eLivestock can be the answer of the data management problem of livestock in the country. We consider that some success factors of e-Livestock in Indonesia have to be formulated, so that all of involved parties in eLivestock in Indonesia can use them to make their eLivestock initiative success. However, those success factors, that specific for e-Livestock in Indonesia, have not been proposed and discussed. Therefore, we do this research to propose and discuss about several success factors of e-Livestock in Indonesia.

\subsection{Previous Works}

There are four previous researches that related to this research. First, Ramadhan and Sensuse (2011) proposed a new paradigm in e-Government called e-Livestock. It is described how e-Livestock as e-Government system and how its application in government. Various kinds of future works are proposed in this study to complete the research about e-Livestock.

Second, Ramadhan et al. (2012a) attempted to formulate the definition of e-Livestock that is specific to Indonesia. The research used hermeneutic to analyze 180 documents that related to the main system that was/being implemented in 5 countries, i.e., in Netherland, Denmark, Japan, Australia and United States of America (USA). The system in Netherland is called as Identification and Registration (I and R) System and started to be used since 1991. Central Husbandry Register (CHR) is the name of the system in Denmark and started to be used since 1993. The system in Japan is called as Individual Cattle Identification Register (ICIR) and started running since 2003. National Livestock 
Identification System (NLIS) is the name of the system in Australia and introduced since 1999 in the State of Victoria. The system in the USA was originally called National Animal Identification System (NAIS) and began to be implemented since 2004. But, then NAIS is terminated on February 5, 2010 and will be replaced with a new system based on the Animal Disease Traceability (ADT) Framework. Until now, the exact form of the new system in USA has not been published.

In the second research, some documents relating to the implementation efforts of similar systems in Indonesia are also being analyzed. The law which deals with livestock and animal health in Indonesia, called the "UU No. 18 Tahun 2009", is also being analyzed by Ramadhan et al. (2012a).

The result of the research in Ramadhan et al. (2012a) is the definition of e-Livestock in Indonesia, i.e., "eGovernment system that is mandatory for the identification, registration, certification and traceability of cows in Indonesia, starting from birth to slaughtered". However, the new definition is not yet validated. Therefore, in the third research, Ramadhan et al. (2012b) validated that definition by asking the opinion of experts and stakeholders in the field of livestock in Indonesia. Several top-level management officers in Indonesian government institutions are also involved in this validation process.

As the result of the third research, after doing some analysis to the interviews opinions, the definition of eLivestock for Indonesia is adjusted. The new definition of e-Livestock for Indonesia is "e-Government system that is mandatory for the identification, registration, documentation and traceability of cows in Indonesia, starting from birth to death".

On the other previous research, that is the 4th research, Ramadhan et al. (2013) has conducted synthesis of 46 journal articles and conference papers. The foremost result of that research is a generic list 36 success factors for e-Government initiative. However, all of that 36 success factors are intended for e-Government initiative in general and not specific to e-Livestock.

\section{MATERIALS AND METHODS}

This research will do some steps that are depicted in Fig. 1. We will take into account all of our previous research. We will take the 36 success factor for eGovernment initiative that are resulted from the research of Ramadhan et al. (2013). We will use the result that has been set forth by Ramadhan et al. (2012a). We also will consider the latest definition of e-Livestock for Indonesia that has been adjusted by Ramadhan et al. (2012b).
As stated by Ramadhan et al. (2012b), that the definition of e-Livestock for Indonesia consists of identification, registration, documentation and traceability activities. Therefore, we interview a stellar of livestock science in Indonesia, to obtain the factors that will make that four activities success. Stellar which is we interview is a professor from one of the main university that related to livestock science in Indonesia. He engaged in a variety of government policies related to livestock management in Indonesia. He was also involved in the formulation of laws relating to livestock and animal health in Indonesia, that is the "UU No 19 Tahun 2009".

In addition, we also take the result of (Ramadhan et al., 2012a) in the interview. This is very useful, particularly on a variety of information about the "e-Livestock like" characteristic in other countries. The stellar can consider that information, so that his answers are more comprehensive.

We combine the result of interview and the success factors for e-Government initiative from the research of Ramadhan et al. (2013), so that we get a new list of success factor that we suggest will important for eLivestock in Indonesia. Then, we compose a questionnaire based on that list of suggested success factors. We use likert-scale in the questionnaire $(1=$ strongly disagree with a success factor and $5=$ strongly agree with a success factor). We hand over the questionnaires to several stakeholders and experts. We involve both of the experts from livestock field and the experts from e-Government field. We called this questionnaire as the first round questionnaires.

We measure the reability of the first round questionnaires. The definition of reliability is the result of the survey (questionnaire) remained largely the same when it is repeated at another time or occasion ( $\mathrm{Yu}$, 2001). There are three things that can reflect the reliability, i.e., stability, equivalence and consistency ( $\mathrm{Yu}$, 2001). Stability can be measured with test-retest approach (Yu, 2001). Equivalence can be measured by creating an alternative form of questionnaires and calculated the correlation between the two results (Brown, 1997). Brown (2002) mentions the name of consistency with the more specific name, that is internal consistency. Cronbach's alpha, as one of internal consistency calculations, has been widely used in various researches. In this research, we use Cronbach's alpha to measure the reability of the first round questionnaires. The value of Cronbach's alpha is in the range from 0 to 1 . In general, the greater the value of Cronbach's Alpha, the more reliable the survey (Yu, 2001). 


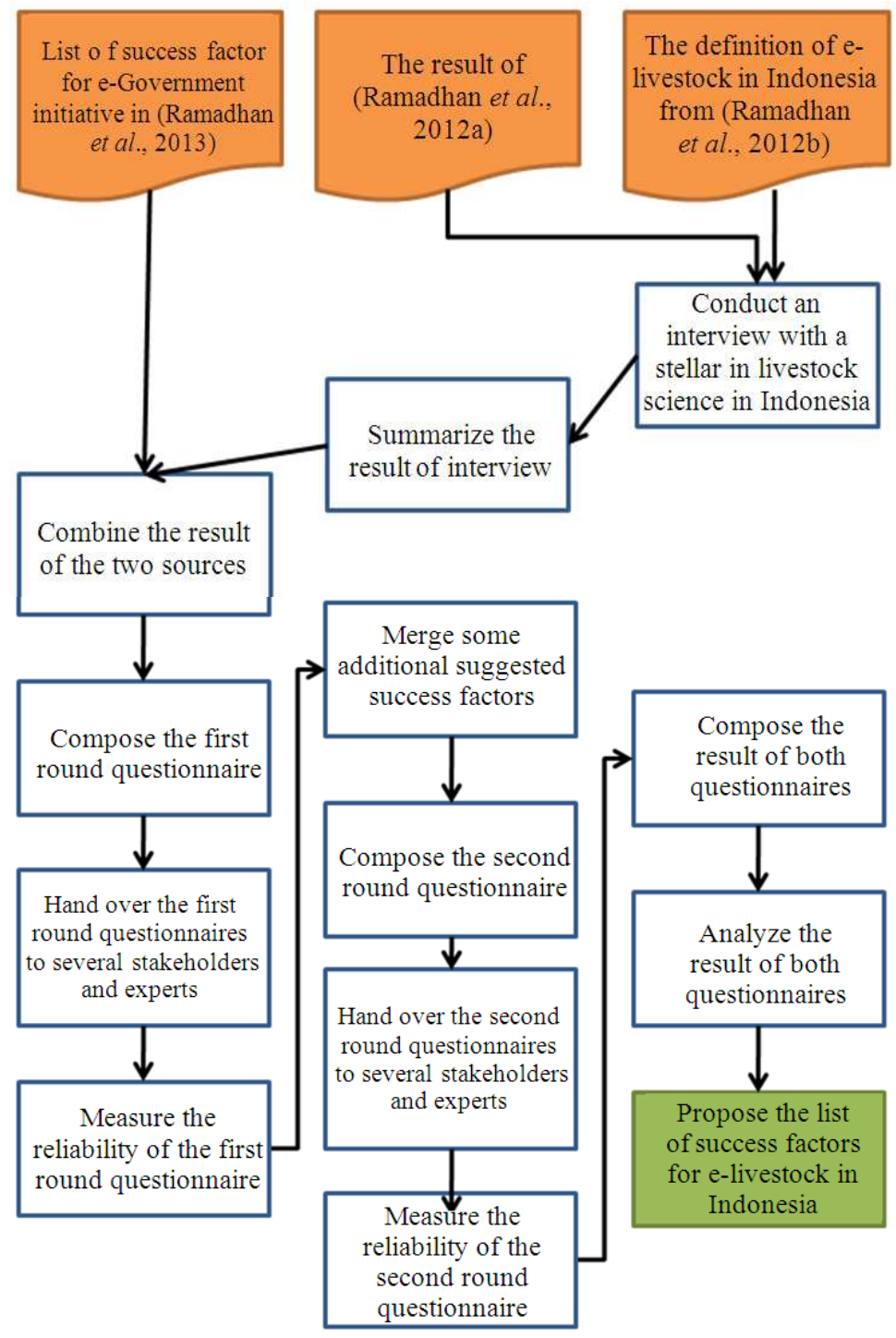

Fig. 1. Research methodology

We deliver the questionnaire twice. This occurs because in the first round, in addition to give rate to the existing suggested success factors, the stakeholders and experts are also allowed to propose any additional suggested success factors that they considered important to the success of e-Livestock in Indonesia.

All the additional suggested success factors from the first round are then merged and put into the second round questionnaire. We hand over again this second round questionnaire to all of the previous involved stakeholders and experts. We also measure the reability of the second round questionnaire using Cronbach's alpha.
Lastly, we combine the result of first round and second round questionnaires. All of them then be analyzed, so that we obtain the list of success factor that are specific for e-Livestock in Indonesia.

\section{RESULTS}

From the result of interview, we get 29 suggested success factors. Those 29 suggested success factors then added into the other 36 suggested success factors that are taken from the research of Ramadhan et al. (2013). At this point, totally we have 65 suggested success factors. 
Thirty six suggested success factors from the research of Ramadhan et al. (2013) are: User and stakeholder involvement; Good planning; Using portal; Training; Good system usability; System campaign; Prototype; Good team skills and expertise; Strong leadership; Good coordination between all project participants; Best practice consideration; Enough funding; Make better business process; Supportive government policy; Political support and stability; Good outsourcing strategy; Supportive ICT infrastructure/service availability; User/citizen computer/internet literacy; Good dan clear organizational structure; International support; System security; Legal framework; Monitoring and evaluation; Good partnership with other institution; Good change management; Supportive cultural Environment; Good system modeling; Deal with bureaucratic; Citizen Relationship Management; Top management support; Support interoperability; Good project management; Good information quality; Good system quality; Good service quality; and Trust.

Twenty nine suggested success factors from the result of interview are: The system should be mandatory, Identify the farmers/the owners of cows; Identify all cows; The identification method of cows are consider social, cultural and religion aspects in Indonesia; The identification method and tool are apply uniformly throughout Indonesia; Identification tool is not easily broken; Identification tool should be disposable in nature; Identification tool should be standardized and accredited by the competent authority; Identification tool should only be produced by agencies that appointed by the government; The identification started since the cows were born; The identification started since the cows entering Indonesia (import); Each cow is given a unique identification number; The information required to determine the productivity of cows should be registered (e.g., number of give birth); Registration occurs when the cows were born; Registration occurs when the cows were imported; Registration occurs each time the cows changed its ownership; Registration occurs each time the cows give birth; Registration occurs each time the cows are given and Artificial Insemination (AI); Registration occurs each time the cows undergo a process of natural mating; Registration occurs when the cows are slaughtered; Identification number of the mother is also registered; The process of identification and registration can only be done by an authorized institution/officer; The farmers/the owners the cows can only do the "notification" to the authorized institution/officer; Every farmers/owner is given a cow ownership documents;
Ownership document may only be issued and filled by competent authorities; An agency is authorized to determine the status of cow productivity based on data that has been registered in the system; The system accommodates the data communication other than through the internet (flexible), particularly in terms of "notifications" process; Provision of "reward" for all the farmers who are willing to get involved; and "Unreward" punishment to all the farmers who are not willing to get involved.

We compose a questionnaire from that 65 suggested success factors using the likert-scale scaling value. This questionnaire is the first round questionnaire. We hand over this first round questionnaire to 32 stakeholders and experts. 28 of them are men and 4 of them are women.

For the reasons of confidentiality and privacy, we can not show any detailed information about each stakeholders or experts. However, we will present some information in Table 1, as cross tabulation of their academic background and job.

All of the 32 stakeholders and experts filled the questionnaires. The value of the Cronbach's alpha of this first round is 0.945 . It means that this first round questionnaire is reliable.

In this first round, some stakeholders and experts propose some other additional success factors. At total, we have 22 new additional success factors from all of them. However, we eliminate 8 of that additional success factors, because they are have been accommodated by other existing suggested success factor. Then, we compose new questionnaire that only contains 14 additional success factors. This new questionnaire is used as the second round questionnaire. Those 14 additional success factors are: The presence of supporting regional policies; the guidelines of the system should easy to understand; Using incremental model of socialization; Using a promoted "pilot run".

Table 1. Cross tabulation of the academic background and job of involved stakeholders and experts

\begin{tabular}{|c|c|c|c|c|c|}
\hline & Bachelor & Doctor & Master & Professor & Total \\
\hline Academician & 0 & 5 & 1 & 3 & 9 \\
\hline Researcher & 0 & 2 & 1 & 3 & 6 \\
\hline $\begin{array}{l}\text { Top level } \\
\text { management in } \\
\text { government } \\
\text { institution }\end{array}$ & 5 & 2 & 6 & 0 & 13 \\
\hline $\begin{array}{l}\text { Top level } \\
\text { management in } \\
\text { private } \\
\text { company }\end{array}$ & 3 & 0 & 1 & 0 & 4 \\
\hline Total & 8 & 9 & 9 & 6 & 32 \\
\hline
\end{tabular}


Table 2. Success factors for e-Livestock in Indonesia

Success factor for e-Livestock in Indonesia

Mean

Good planning

Using portal

Training

Good system usability

System campaign

Prototype

Good team skills and expertise

Strong leadership

Good coordination between all project participants 4,46

Best practice consideration

Enough funding

Make better business process

Supportive government policy

Supportive ICT infrastructure/service availability 4,32

User/Citizen computer/internet Literacy

Good dan clear organizational Structure

System security

Legal framework

Monitoring and Evaluation

Good partnership with other institution $\quad 4,32$

Good change management 4,21

Supportive cultural environment 4,07

Good system modeling $\quad 4,29$

-

$\begin{array}{ll}\text { Top management support } & 4,39\end{array}$

Good project management $\quad 4,14$

Good information quality: Accuracy, relevance, completeness, timeliness 4,64

Good system quality: Accessibility, reliability and availability 4,57

Good service quality: Responsiveness, assurance and empathy 4,54

The system should be mandatory 4,32

Identify the farmers/the owners of cows 4,46

4,36

The identification method and tool are apply uniformly throughout Indonesia 4,14

Identification tool is not easily broken 4,36

Identification tool should be standardized and accredited by the competent authority 4,18

The identification started since the cows were born 4,43

The identification started since the cows entering Indonesia (import) 4,46

Each cow is given a unique identification number 4,39

The information required to determine the productivity of cows should be registered (e.g. number of give birth,)

4,39

Registration occurs when the cows were imported 4,32

Registration occurs each time the cows changed its ownership 4,11

Registration occurs each time the cows give birth 4,11

$\begin{array}{ll}\text { Registration occurs when the cows are slaughtered } & 4,14 \\ \text { Identification number of the mother is also registered } & 4,50\end{array}$

The process of identification and registration can only be done by an authorized institution/officer 4,11

Every farmers/owner is given a cow ownership documents 4,54

Ownership document may only be issued and filled by competent authorities 4,61

An agency is authorized to determine the status of cow productivity based on data that has been registered in the system 4,11

The system accommodates the data communication other than through the internet (flexible),

particularly in terms of "notifications" process

Provision of "reward" for all the farmers who are willing to get involved

The presence of supporting regional policies

The guidelines of the system should easy to understand 4,57

Using incremental model of socialization 4,50

$\begin{array}{ll}\text { Record the medical history, especially in certain } & 4,00 \\ \text { diseases the involving in e-Livestock should be free for farmers/owners } & 4,25\end{array}$

$\begin{array}{lr}\text { diseases the involving in e-Livestock should be free for farmers/owners } & 4,25 \\ \text { Registration of the event of death or missing } & 4,25\end{array}$

Registration occusr when the cows getting treatment (e.g., medicine) 4,36

Creating economic implications of the program 4,11

The government's commitment should be stable and consistent 4,82

e-livestock development funds should be protected from corruption $\quad 4,50$ 
There is a certification process for the executing agencies; Recorded the history of reproductive failure; Record the medical history, especially in certain diseases; The involving in e-Livestock should be free for farmers/owners; Registration of the event of death or missing; Registration occusr when the cows getting treatment (e.g., medicine); Cows contest is used as a measure of success; Creating economic implications of the program; The government's commitment should be stable and consistent; and e-livestock development funds should be protected from corruption.

We hand over the second round questionnaires to the previous involved 32 stakeholders and experts. However, there are only 28 of them that answer and fill this second round questionnaire. The value of the Cronbach's alpha of this first round is 0.825 . It means that this second round questionnaire is also reliable.

Because only 28 stakeholders and experts who fill both questionnaires, then we will only use the results of questionnaires from 28 stakeholders and experts in subsequent process. As a consequence, we pull out 4 first round questionnaire data from our analysis. Those 4 data are come from: 1 academician (hold a master degree), 1 top level management in government institution (hold a master degree) and 2 top level management in government institution (hold a $\mathrm{PhD}$ ).

We combine the 28 data that resulted from first round questionnaire and the 28 data form second round questionnaire. At this step, we get 65 suggested success factors that exist in first round questionnaire and 14 suggested success factors that exist in second round questionnaire. Then, we calculate the mean of each 79 suggested success factors.

As the result, we only consider the suggested success factors that their mean are equal or greater than 4 . There are only 62 suggested success factors that fulfill the criteria. Therefore, we consider that this 62 suggested success factor are become what we called as "the success factor for e-Livestock in Indonesia". The list of those 62 final success factor can be seen Table 2.

\section{DISCUSSION}

The first 30 success factors in Table 2 are related to e-Government initiative in general and the other 32 is more specific to e-Livestock in Indonesia. However, all of the success factors that depicted in Table 2, have the same degree. No one is more important and less important, all of them are equal. We propose that in practice, to make their initiative success, all of the 62 success factors that resulted from this research have to exist and be accommodated by all parties that involved in the e-Livestock initiative in Indonesia.

\section{CONCLUSION}

This research has succeeded in proposing the 62 success factors for e-Livestock in Indonesia. Those 62 success factors can assist all parties that involved in the eLivestock initiative in Indonesia, especially in supporting the government's Beef Self-Sufficiency Program (PSDS).

E-Livestock is a new paradigm in E-Government, especially in Indonesia. Because it is new, the research on e-Livestock is still very open. This research is able to maximize the results of several previous researches. This research has added to the body of knowledge in eLivestock research and in e-government research in common. Various further researches can be conducted using the result of this research and to enrich the research in e-Livestock.

\section{REFERENCES}

Assar, S., I. Boughzala and I. Boydens, 2011. Back to Practice, a Decade of Research in E-Government. In: Practical Studies in E-Government, Assar, S., I. Boughzala and I. Boydens (Eds.), Springer, New York, pp: 1-12.

BPS, 2011. Penduduk Indonesia Menurut Provinsi 1971, 1980, 1990, 1995, 2000 dan 2010. Badan Pusat Statistik.

Brown, J.D., 1997. Statistics Corner: Questions and answers about language testing statistics: Reliability of surveys. Shiken: JALT Testing Evaluation SIG Newsletter, 2: 17-19.

Brown, J.D., 2002. Statistics corner: Questions and answers about language testing statistics: Skewness and kurtosis. Shiken: JALT Testing Evaluation SIG Newsletter, 6: 17-18.

DGLAH, 2009. Statistik Peternakan. 1st Edn., Directorate General of Livestock and Animal Health Press, Indonesia.

DGLAH, 2011. Blueprint Program Swasembada Daging Sapi 2014. 1st Edn., Directorate General of Livestock and Animal Health Press, Indonesia.

Heeks, R., 2006. Implementing and Managing EGovernment: An International Text. 1st Edn., SAGE Publications, ISBN-10: 0761967923, pp: 293.

Lofstedt, U., 2008. E-services for and by Citizens: Towards E-participation and Social Systems Design for Development of Local Public E-services. Ph.D. Thesis, Mid Sweden University, Sweden.

Malau, A., 2010. Indonesia Import 70 ribu Ton Daging Sapi Per Tahun. 
Ramadhan, A. and D.N. Sensuse, 2011. E-Livestock as a new paradigm in e-government. Proceedings of the 3rd International Conference on Electrical Engineering and Informatics, Jul. 17-19, IEEE Xplore Press, Bandung, pp: 1-4. DOI: 10.1109/ICEEI.2011.6021711

Ramadhan, A., M. Muladno, D.I. Sensuse and A.M. Arymurthy, 2012a. E-Livestock: Its definition for Indonesia. Eur. J. Sci. Res., 84: 304-327.

Ramadhan, A., M. Muladno, D.I. Sensuse and A.M. Arymurthy, 2012b. E-Livestock in Indonesia: Definition adjustment, expected benefits and challenges. Proceeding of the International Conference on Advanced Computer Science and Information System, Dec. 1-2, IEEE Xplore Press, Depok, Indonesia, pp: 131-136.

Ramadhan, A., Sensuse, D.I. Muladno and A.M. Arymurthy, 2013. Synthesizing success factors for e-government initiative. Res. J. Applied Sci., Eng. Technol. In Press.
Sinjal, D., 2011. PSDS 2014 dengan Input Data yang Benar. Agrina.

Wang, J.F. and T. Zeng, 2009. Citizen-centered egovernment strategy governance framework: Case of China. Proceedings of International Conference on Web Information Systems and Mining, Nov. 7-8, IEEE Xplore Press, Shanghai, pp: 589-593. DOI: 10.1109/WISM.2009.124

WB, 2011. Definition of E-Government. The World Bank Group.

$\mathrm{Yu}$, C.H., 2001. An introduction to computing and interpreting cronbach coefficient alpha in SAS. Arizona State University. 